\title{
A PROPOSTA DE GESTÃO TERRITORIAL DAS TERRAS INDÍGENAS, COMO MEIO DE ALCANÇAR A SUSTENTABILIDADE
}

\section{The Proposal of Indigenous Lands Management by Means of Achieving Sustainability}

\author{
Roberto dos Anjos Dias \\ Mestrando em Desenvolvimento Rural Sustentável - UNIOESTE \\ rd_dias@yahoo.com.br \\ Angelica Siqueira \\ Mestranda em Desenvolvimento Rural Sustentável - UNIOESTE \\ angelicacdi@yahoo.com.br \\ Nardel Luiz Soares Silva \\ Coordenador do Programa de Pós Graduação de Desenvolvimento Rural Sustentável - UNIOESTE \\ nardel.silva@unioeste.br
}

Artigo recebido em 17/08/2015 e aceito para publicação em 16/08/2016

DOI: $10.12957 /$ tamoios.2017.18214

\begin{abstract}
Resumo
Considerando a atual problemática mundialmente discutida em relação ao desenvolvimento sustentável e os modelos sustentáveis de sociedade, percebe-se a necessidade de contribuir no sentido de apontar direções e metodologias para alcança-las. O presente estudo tem por objetivo sugerir o uso do modelo de Gestão Territorial das Terras Indígenas para articular estratégias e promover as potencialidades materiais e imateriais de um território, seguindo princípios que permitam constituir a práxis de um modo de vida sustentável. Uma vez que as terras indígenas apresentam características como delimitação geográfica, princípios comunitários de se manter em equilíbrio com a natureza, instituições de apoio, entre outras que possibilitam servirem de modelo de sociedades sustentáveis. A proposta foi levantada a partir de revisão teórica de conceitos e práticas que propiciam embasamento para discussão do desenvolvimento territorial sustentável. Conclui-se então que projetos de Gestão Territorial das Terras Indígenas que respeitem a autonomia e permitem a participação dos indígenas considerando sua cultura de sustentabilidade do território, servem de modelo para promover o desenvolvimento de uma sociedade sustentável.
\end{abstract}

Palavras-chave: Sociedades sustentáveis, gestão, territórios, ética, terras indígenas.

\begin{abstract}
Considering the current problem, discussed around the world, about the sustainable development and sustainable models of society, it is clear the necessity of contribute pointing directions and methodologies to reach this sustainability. The research aims to suggest the utilization of the territorial management model of Indigenous lands to articulate strategies and promote the material and immaterial potentialities of a territory, according sustainable principles to build the praxis of the sustainable mode of life. Once the indigenous lands have characteristics as geographical delimitation, communitarian principles to maintain a balance with nature, support institutions, among others that enable be models to a sustainable society. The proposal was raised from theoretical review of concepts and practices that provide base to discussion of sustainable territorial development. It was concluded that projects of territorial management model of Indigenous lands which respect the autonomy and the participation of Indigenous considering their culture of sustainable territory, can be used as a model to promote the development of a sustainable society.
\end{abstract}

Key-words: sustainable societies, management, territories, ethics, indigenous lands. 


\section{INTRODUÇÃO}

Sustentabilidade é um termo que surgiu no século XVIII na Alemanha devido à preocupação com o uso racional das florestas (BOFF, 2015). Entretanto, tornou-se popular graças a seu uso como adjetivo de desenvolvimento desde meados da década de 1960, quando a percepção de que os recursos naturais são finitos vem à tona. Com este uso, o termo sustentabilidade ganha seu sentido hegemônico, isto é, da utilização racional dos recursos naturais de forma que estes não se esgotem.

Dessa forma, o termo sustentabilidade foi inserido como adjetivo do termo desenvolvimento. Considera-se uma composição de conceitos aparentemente contraditória por conciliar um processo de exploração intensiva, crescimento econômico e inovação tecnológica, próprios do desenvolvimento, com o movimento de regeneração de longo prazo e de inúmeras variáveis presentes em estados de equilíbrio ecológico. Uma tarefa extremamente difícil, pois, como afirma Baroni (1992), há uma necessidade de cautela quando se trata de produção e ambiente, pois "a capacidade e a velocidade da sociedade industrial contemporânea na criação de novos produtos e situações de risco é maior do que a capacidade da ciência de verificação de suas consequências" (BARONI, 1992, p.24).

Entretanto, percebe-se que o atual modelo produtivo hegemônico de crescimento econômico é insustentável em seu viés financeiro, social, e ambiental, pois pauta-se na exploração ilimitada de recursos finitos, o que é contraditório por essência. Como afirma Cavalcanti (2012, p.37), "pela óptica da natureza, não faz nenhum sentido falar-se em crescer [...] de forma sustentável. Essa possibilidade simplesmente não é parte dos processos naturais. Com efeito, no ecossistema, processos de crescimento contínuo [...] terminam inevitavelmente em desastre". Bem como, tal modelo tem como resultado lucros que não se traduzem em qualidade de vida e são excludentes para maior parte da população mundial (BOFF, 2015).

Neste sentido, Leonardo Boff (2015) aponta que o desafio da sociedade moderna é desenvolver um modo sustentável de vida, no qual a sustentabilidade não pode ser reduzida a apenas um elemento do crescimento econômico e sim, estar presente em diversas dimensões da vida. Para o autor, a sustentabilidade alcança novas implicações de ordem social, econômica, espiritual, entre outras, além da ambiental. Em todas as dimensões abordadas, a noção geral que perpassa o termo sustentabilidade é de resiliência e perpetuação, isto é, da qualidade de existir de maneira estável ao longo do tempo.

Sendo assim, acredita-se que para atingir a sustentabilidade se faz necessário pensar em propostas holísticas, apontar direções e metodologias de base interdisciplinar considerando a complexidade do tema.

A Gestão Territorial das Terras Indígenas ${ }^{1}$ é um termo que ganhou espaço nos debates sobre desenvolvimento territorial, desenvolvimento sustentável, conservação ambiental e controle territorial, devido às suas características como delimitação geográfica: o objetivo comunitário de manter-se em equilíbrio com a natureza, a presença de diversas instituições - com o objetivo de desenvolver de maneira sustentável esses territórios -, entre outras motivações. Considerando tais características, entende-se que as terras indígenas têm possibilidades de se estruturar dentro do território brasileiro como sociedades sustentáveis, isto é, pequenos territórios baseados nos princípios da sustentabilidade de acordo com o estabelecido por cada sociedade, como proposto por Diegues (2003). 
Neste sentido, sugere-se neste estudo que se utilize a noção de gestão "territorial das terras indígenas" para articular conceitos e estratégias para a promoção das potencialidades materiais e imateriais de um território e, seguindo princípios sustentáveis, constituir a práxis do modo de vida sustentável.

\section{A GESTÃO TERRITORIAL DE TERRAS INDÍGENAS COMO MEIO DE SE ALCANÇAR A SUSTENTABILIDADE}

Sustentabilidade é um termo que demanda sempre a articulação de mais de um tema. Assim como o desenvolvimento sustentável, geralmente baseia-se no tripé: economia, meio ambiente e sociedade. $\mathrm{O}$ desafio que se apresenta é de acrescentar outras dimensões no planejamento da sustentabilidade. Portanto, necessita-se de uma abordagem que seja capaz de responder por múltiplos interesses, e esta se sugere ser o território.

O território é um conceito que pode ser definido como uma parcela do espaço apropriada nos quais indivíduos, grupos ou instituições exerce o poder (RAFFESTIN, 1993), isto é, o território é uma parcela do espaço produzida por uma rede de relações sociais, culturais, econômicas e políticas (CANDIOTTO, 2004). É historicamente produzido e reproduzido. Segundo Saquet (2015, p.45), "O território é produto das relações sociedade-natureza e condição para a reprodução social [e] os territórios são produzidos espaço-temporalmente pelo exercício do poder por determinado grupo ou classe social e por suas respectivas territorialidades cotidianas".

Em outras palavras, é no território que desenrolam as tramas políticas, culturais, econômicas, entre outras. E essas tramas, por sua vez, destroem, rearranjam e geram novos territórios. Em vista disso, compreende-se que o território é categoria relevante para planejamentos de gestão e desenvolvimento, pois a nosso ver, é na escala do território que podem ser identificados os atores e processos que o constroem.

Cabe esclarecer que o território é comumente abordado a partir das dimensões simbólica e material, em que na primeira este é produzido através de relações de apropriação de símbolos existentes no território, como elementos naturais, elementos construídos pelo homem, entre outros, e na dimensão material, o território é produzido através de relações de domínio dos recursos, em ações que envolvem principalmente o poder do Estado (HAESBAERT, 2006).

A título de ilustração, cabe esclarecer, de forma simplista, que o Estado domina os recursos naturais de um território e delimita suas fronteiras. Por outro lado, populações tradicionais apropriam-se de um território onde dependem de seus recursos para sobrevivência e dotam esta parcela do espaço de símbolos, atrelando aquele recorte à sua identidade.

A existência de terras indígenas demarcadas possibilita ao povo indígena, que ocupa o território, manifestar tanto a dominação quanto a apropriação do território. Além do poder do Estado que reconhece os direitos indígenas sobre o território, os índios têm legitimado mais do que sua apropriação (que independe do Estado e é reconhecida nas legislações indigenistas), o seu domínio do território, podendo restringir o acesso às terras, organizar-se de forma tradicional e utilizar os recursos naturais presentes no território conforme suas necessidades. Por outro lado, onde não há a demarcação, os indígenas vivem em situação de insegurança territorial, manifestando mais fortemente a apropriação dos símbolos através de sua cultura (DIAS, 2014). 
Tais características tornam o território adequado para pensar ações com base em conhecimentos diversificados e para a compreensão das relações de poder que se anulam, articulam ou competem em um espaço delimitado, principalmente aliado ao recorte para terras indígenas, que se constituem de territórios onde perpassam relações de poder vindas de culturas, políticas, organizações e instituições diversas que visam à conservação da biodiversidade e dos aspectos culturais ali presentes.

Para Little (2006), existem duas agendas políticas que atuam e demandam instrumentos técnicos para a gestão de terras indígenas, que seriam "[...] a agenda de direitos étnicos e territoriais dos povos indígenas e a agenda ambientalista da sustentabilidade (LITTLE, 2006, p.16)". Para conciliar estes objetivos é utilizada a noção de "Gestão Territorial das Terras Indígenas", a qual não possui uma definição rígida, mas se configura num mote (SOUZA e ALMEIDA, 2013, p. 39) ou uma "lona de proteção" sob a qual diversos assuntos são debatidos em prol da sustentabilidade das terras indígenas (GTZ, 2009, p. 19).

Em vista da variedade de conceitos sobre esse tema, mas que muitas vezes sugerem significados semelhantes - apesar de nomeadas de forma diferente - Little (2006, p.20) buscou sistematizar informações acerca do que se entende por "Gestão Territorial das Terras Indígenas", resultando na identificação de cinco conceitos chave que compõe o campo de atuação da "Gestão Territorial em Terras Indígenas: (i) ordenamento territorial, (ii) ordenamento ambiental, (iii) "estão territorial, (iv) gestão ambiental e (v) etnozoneamento. Por sua vez, cada um desses conceitos constitui-se de ações políticas, técnicas e diferentes metodologias realizadas por agentes diversos.

Nesse sentido, Little (2006, p.21) compreende que a noção de "Gestão Territorial das Terras Indígenas" serve como conceito síntese combinando a dimensão política do controle territorial das terras indígenas com a dimensão ambiental das ações que visam sustentabilidade, e também engloba atividades de ordenamento territorial e de gestão ambiental como parte fundamental da sua implementação.

Através da utilização da "Gestão Territorial das Terras Indígenas", delimita-se um campo de atuação e se estabelece um norte de atuação, e assim, tem-se um conjunto de conceitos e técnicas que podem ser direcionadas ao atendimento das demandas das duas agendas políticas supracitadas.

Antes de prosseguir, cabe esclarecer a estreita relação de "Gestão Territorial das Terras Indígenas", gestão territorial e desenvolvimento territorial, pois há diversas semelhanças e diferenças sutis além das nomenclaturas. Ambas as abordagens lidam com a complexidade de fatores presentes em um determinado território, buscando alteração nos padrões de vida da comunidade em questão.

A gestão territorial opera no campo político, e assim é realizada segundo os interesses sociais, econômicos e políticos do grupo social presente no território, contendo certa preocupação com o manejo ambiental (LITTLE, 2006, p.20). Dessa forma, a atuação dos envolvidos na gestão territorial terá objetivos definidos a partir da organização política local que podem contemplar a produção econômica para comércio ou consumo comunitário, recuperação e manutenção do ambiente, segurança alimentar, entre outros segmentos.

A aplicação da "Gestão Territorial em Terras Indígenas" se dá em função da importância que a terra e o território apresentam para os povos indígenas, tendo significado fundamental para a reprodução social e cultural, por ser mais ampla e abranger o tema ambiental e por atender o interesse de diferentes atores e instituições que convergem diferentes objetivos em um só (GTZ, 2009). 
Por outro lado, segundo Boisier et al (1995, p. 01), o desenvolvimento territorial inclui o desenvolvimento em micro localidades, como comunidades, e meso localidades, como regiões. Ainda segundo o autor, o objetivo do desenvolvimento territorial é triplo: 1) o aperfeiçoamento do território entendido não somente como um suporte estrutural dos elementos naturais, mas como um sistema físico e social estruturalmente complexo, dinâmico e delimitado. 2) o aperfeiçoamento da sociedade ou comunidade que habita o território e que tem este como referência de identidade e cultura. 3) o aperfeiçoamento de cada pessoa que habita este território. O foco no desenvolvimento territorial é voltado à mudanças socioeconômicas estruturais e prevê a articulação entre as populações locais e demais escalas de poder e gestão, como o Estado por exemplo, em torno de um projeto de desenvolvimento voltado ao que o grupo local define como seu território de atuação (RAMBO; RUCKERT, 2008, p. 97-98).

Percebe-se então que o desenvolvimento territorial é um conceito que pode contribuir para o desenvolvimento de terras indígenas através da valorização do potencial humano e da compreensão do território como um sistema integrado e complexo. Entretanto, compreende-se que o desenvolvimento territorial mantém como foco a evolução, isto é, atem-se à ideia da passagem de um determinado estado para outro considerado melhor, enquanto a gestão territorial está mais associada com a ideia de viver bem.

O desenvolvimento territorial, mesmo seguindo premissas de cooperação e solidariedade, ainda preza pela presença de atividades econômicas no território que diferem do sistema econômico hegemônico (RAMBO e RUCKERT, 2008). O seu uso pode ser adequado para atender necessidades de geração de renda de terras indígenas, porém, não responde teoricamente a todos os territórios indígenas. Entretanto, o conceito de gestão territorial pode conter as premissas do desenvolvimento territorial, mas não o contrário.

Devido à grande diversidade territorial, social, econômica, e ambiental, os gestores e os atores apresentam diferentes interesses e objetivos para cada terra indígena. Assim, através de projetos de gestão territorial das terras indígenas, são articulados os interesses de diferentes órgãos que planejam suas ações para essas terras, como a Fundação Nacional do Índio (FUNAI), a Secretaria Especial de Saúde Indígena (SESAI), o Ministério do Meio Ambiente (MMA) e o Ministério do Desenvolvimento Agrário (MDA) - que possuem interesse na conservação ambiental e segurança alimentar -, ONGs indigenistas nacionais e internacionais, e, sobretudo, os interesses das organizações e sociedades indígenas, além de outras instituições parceiras.

\section{A PRESENÇA DE PRINCÍPIOS ÉTICOS E VALORES SUSTENTÁVEIS EM TERRAS INDÍGENAS}

Considera-se que para a realização do desenvolvimento do modo sustentável de vida, as ações devem ser baseadas nos valores existentes na sociedade que ocupa o território e estes valores vão definir o peso que terá cada dimensão do desenvolvimento.

Sendo assim, é de suma importância o reconhecimento de que os povos indígenas possuem uma relação espiritual com o ambiente, e "apesar de uma grande variedade em seus modos de vida, na maior parte de seus modelos de sustentabilidade há uma relação de profunda interdependência entre povos indígenas, seu território e recursos naturais" (SOUZA e ALMEIDA, 2012, p.28). Seus valores, portanto, diferem da sociedade não indígena, pois apresenta diferentes interações com o meio. 
Segundo Smith e Guimarães (2010), ao fim de 1990, o fator ambiental passa a ser considerado no processo de identificação de terras indígenas e aliado à demanda das organizações indígenas por melhores formas de gestão, "medidas de proteção e conservação ambiental passam a ser interpretadas pelos indígenas como oportunidades de adquirir apoio para a realização de atividades sustentáveis, numa perspectiva mais ampla de gestão dos territórios" (SMITH; GUIMARÃES, 2010, p. 05).

Nesse sentido, percebe-se que as atividades tradicionais de gestão foram estrategicamente absorvidas pelos indígenas, como forma de atrair recursos e parceiros para a realização de seus projetos, mas sem deixar de se importar com a conservação ambiental e dar a gestão territorial um sentido mais harmônico e abrangente (SMITH e GUIMARÃES, 2010, p. 09).

Acredita-se ser necessário estimular ações que atendam os desejos da sociedade presente no território. Tomemos como exemplo o caso da premissa do "bem viver" (teko porã) Guarani e de outros povos indígenas da América Latina para os quais a concepção de qualidade de vida é sinônimo da convivência em harmonia do indivíduo consigo mesmo, com a comunidade e com a natureza (ACOSTA, 2016). Assim, não faz sentido investir em produção e crescimento econômico sem garantir os elementos que a cultura local determina como fundamental para sua existência.

A existência de valores culturais transmitidos de geração para geração no que diz respeito a ações sustentáveis, otimiza o tempo e o orçamento da instituição planejadora, cabendo às políticas públicas atenderem as demandas materiais e de capacitação, bem como promover o estímulo a mobilização da coletividade.

A gestão territorial depende, em grande parte, da articulação da coletividade. A execução de projetos - iniciada por impulso de gestores externos como o Estado, a iniciativa privada, e ONGs - necessita de continuidade pela comunidade. A descontinuidade de projetos é um dos principais fatores de insucesso nos resultados previstos, além de causar desânimo e descrédito das instituições. (SOUZA e ALMEIDA, 2012; RCA, 2013).

Conforme o pressuposto anterior, é necessário considerar a presença do capital humano que atua no campo individual "determinado pelos graus de nutrição, saúde, educação cultura e segurança da população" (BOFF, 2015, p.133), e do capital social, que é resultado de um processo histórico e construído a partir das relações sociais da comunidade como normas, valores, grau de confiança, cooperação e solidariedade, que torna possível a participação democrática dos indivíduos (BOFF, 2015; FREY, 2003).

O capital social é um elemento estratégico que perpassa todo o processo de desenvolvimento e está presente na definição dos objetivos com base em valores comunitários, no planejamento e implementação de metodologias, na distribuição dos resultados e na continuidade das atividades.

Este capital social também se dispõe como um banco de dados, que em muitos territórios tradicionais possui milhares de anos de conhecimento armazenados sobre os recursos humanos e naturais do território. Indica-se que a gestão de territórios tem a possibilidade de utilizar este capital como base de informações e planejar ações a partir dele, criar tecnologias adequadas a determinado ecossistema e que respondam a determinadas características culturais, e não transferir métodos criados com base externa. Quanto maior a interação da comunidade e do seu respectivo ecossistema e o respeito por essa relação, maior será a possibilidade do desenvolvimento sustentável se tornar viável (BOFF, 2015, p.138 - 139). 
Para que haja sustentabilidade, entende-se como necessário a participação política da comunidade em todas as etapas do processo de desenvolvimento, fazendo com que seja uma realização democrática e que as mudanças geradas sejam internalizadas pela comunidade através do sentimento de cooperativismo, garantindo maior durabilidade das transformações (BUARQUE, 1999).

A participação indígena em programas e projetos de gestão territorial é garantida pela Convenção $\mathrm{n}^{\circ} 169$ da Organização Internacional do Trabalho, à qual o Brasil é signatário, além da Declaração Internacional dos Povos Indígenas da ONU, entre outras. Porém, o direito de consulta prévia às informações sobre políticas públicas do interesse dos indígenas estabelecidas nestes documentos por vezes é ignorado, principalmente pelo Estado. Não há como construir um desenvolvimento com sustentabilidade ambiental, econômica e social sem a participação coletiva, principalmente para terras indígenas que são de uso exclusivo para o coletivo.

Destaca-se positivamente que o esforço de construir estratégias de gestão territorial muitas vezes parte dos próprios índios, "às vezes com a ajuda de organizações parceiras, instituições públicas responsáveis por atender suas demandas e pelas próprias associações indígenas" (RCA, 2013, p.19). Bem como a participação é considerada por parte das instituições parceiras como imprescindível para a realização da gestão e desenvolvimento sustentável do território.

Souza e Almeida (2012) concluem que:

É importante ressaltar, contudo, que a lógica de projetos pensados e elaborados "de dentro" tem muitas vantagens em relação aos projetos que tradicionalmente eram trazidos pelo Estado brasileiro e impostos às sociedades indígenas que, em tempos passados, eram consideradas transitórias e em processo de aculturação. Deste modo, com todos os problemas acima apontados, nos casos em que o protagonismo indígena está garantido - sendo o projeto desenvolvido segundo as aspirações da comunidade, ao invés de resultado do que pensa a burocracia estatal - os projetos sociais têm um papel muito importante na viabilização da gestão territorial Indígena, visto que refletem um planejamento interno (SOUZA e ALMEIDA, 2012, p.195).

A participação coletiva dos indivíduos de um território fortalece as ações de transformação social. $\mathrm{O}$ trabalho em conjunto para alcançar objetivos comuns permite a construção da consciência do grupo, em relação aos impactos gerados pela exploração intensiva do meio ambiente, resultado do um consumo excessivo. As mudanças necessárias não se limitam às formas de exploração, mas principalmente, na organização social e participação de quem consome.

\section{O DESENVOLVIMENTO ECONÔMICO EM TERRAS INDÍGENAS COM VISTA A SUSTENTABILIDADE}

Considera-se como não sustentável o desenvolvimento que vise amenizar as mazelas sociais, "como resultado secundário de um processo de crescimento econômico, ainda que local", (MANCE, 2004, p.62). Para o desenvolvimento econômico sustentável, acredita-se que os valores econômicos não devem estar acima dos valores sociais como solidariedade, cooperativismo e do "bem viver", e que a estrutura da organização econômica local deve estar baseada nesses valores para alcançar a sustentabilidade. 
Embora o desenvolvimento econômico não assuma protagonismos neste estudo, como geralmente se apresenta em outras abordagens, não é descartado seu papel de importância no planejamento da "Gestão Territorial das Terras Indígenas". É importante notar que o processo histórico do Brasil interferiu fortemente sobre os territórios indígenas, desestruturando seus sistemas produtivos e aumentando sua dependência dos órgãos de assistência e da geração de renda. $\mathrm{O}$ desenvolvimento econômico no processo de gestão do território pode garantir autonomia e independência do mesmo (SOUZA e ALMEIDA, 2012, p. 180).

Dessa forma, o planejamento econômico na gestão territorial pode se caracterizar como estratégia para melhorar a qualidade de vida de um território, desde que a sustentabilidade seja condição determinante nos modos de produção, e não elemento inserido após a produção estabelecida.

Para Souza e Almeida (2012, p. 195), a dimensão econômica de "Gestão Territorial das Terras Indígenas" deve estar sustentada por 3 bases de aproveitamento das características materiais e imateriais do território. São elas: 1) planejamento das atividades de acordo com as características culturais do território; 2) investimento em atividades tradicionais dominadas pelas populações locais, mesmo utilizando técnicas externas; 3) possibilidade de implantação de novas atividades com técnicas não tradicionais, porém, que sejam economicamente viáveis e que respeitem as características socioculturais e ambientais.

Seguindo tais premissas, o modo de exploração e produção alternativo e sustentável pode ser incentivado através de assistência técnica de órgãos governamentais, associações ou ONGs, profissionalizando os indígenas e dando o suporte necessário para aumentar a produção e a qualidade dos alimentos, bem como estimular novos tipos de produção como agro florestas e a agricultura consorciada.

Algumas destas ações atualmente estão se materializando no Brasil através de organizações populares que se apresentam como uma "outra economia". "Muitos produtores assim organizados estruturam um tipo de economia à margem do mercado, criando redes de produção e troca, não baseada na moeda oficial nem comandada pelo lucro (MONTIBELLER-FILHO, 2007, p.85)"'. Tais organizações sociais se inscrevem no espaço através de associações, grupos informais, cooperativas entre outros. Estão presentes em 53\% dos municípios brasileiros, distribuídos 54,9\% em áreas rurais, 34,8\% em áreas urbanas, e 10,4 \% simultaneamente nas duas áreas (GAIGER, 2014). Embora ainda representem um número inferior nos empreendimentos, há um aumento expressivo de estabelecimentos de economia solidária nos últimos anos (ANTEAG, 2009).

Porém, sem ética, sem estímulo ao capital humano e social e sem a consciência da necessidade de novas formas de produção, tais empreendimentos são enfraquecidos com as dificuldades e abandonados pelos membros, assim como os princípios de solidariedade que garantem o sucesso da iniciativa (SINGER, 2002).

Portanto, sugere-se que a produção, comercialização e distribuição sigam os princípios da economia solidária "em razão dos seus benefícios sociais e ecológicos, por sua capacidade de geração de trabalho e renda, distribuição de riqueza e promoção do bem-viver das pessoas" (MANCE, 2004, p. 68).

A economia solidária em terras indígenas pode ser realizada através de redes de trocas - de alimentos, sementes, mudas e insumos - entre comunidades tradicionais ou inseridas em mercados locais e regionais, como também, estabelecendo parcerias com outras organizações de mesma essência, porém, sempre garantindo a preservação da cultura local. 
Algumas atividades já estão sendo realizadas, desde a produção de mel à arte gráfica $^{3}$, em que produtos indígenas são comercializados e possuem maior valorização devido a sua indicação geográfica. A indicação geográfica trata-se um instrumento jurídico e econômico previsto na Lei 9.279/96, que têm o objetivo de agregar valor a produtos associando estes aos seus territórios, além de ser comumente utilizado como estratégia para incentivar o desenvolvimento territorial.

\title{
TERRAS INDÍGENAS: MODELOS DE SOCIEDADES SUSTENTÁVEIS
}

Atualmente, existem 588 terras indígenas (FUNAI, 2016) em todos os biomas brasileiros, constituindo-se em territórios delimitados dentro do país que possuem certa autonomia de gestão, como também características territoriais, culturais e sociais diversificadas.

Como é demonstrado no documento "Gestão Ambiental e/ou Territorial de/em Terras Indígenas" (2008),

\begin{abstract}
Há quase que uma unanimidade no reconhecimento de que a conjuntura atual dos povos e terras indígenas assume nuances distintas nas diferentes regiões do país. Isso se deve a pelo menos cinco fatores: (i) diversidade de culturas, histórias de contatos e processos de territorialização dos povos indígenas, (ii) diferentes contextos regionais, étnicos e socioeconômicos, (iii) natureza variada das ameaças que aí pesam sobre povos e terras indígenas, (iv) distintas alianças e correlações de forças entre atores regionais, e (v) múltiplas demandas e capacidades de acompanhamento, gerenciamento e articulação das próprias comunidades e organizações indígenas (GTZ, 2009, p.3).
\end{abstract}

Devido a estas múltiplas características, não é possível conceber um modelo homogêneo de sustentabilidade e desenvolvimento sustentável para terras indígenas, portanto, percebe-se a importância de retomar a ideia proposta por Diegues (1992), de sociedades sustentáveis, ou seja, resgatar a importância de que "cada sociedade se estruture em termos de sustentabilidades próprias, segundo suas tradições culturais, seus parâmetros próprios e sua composição étnica específica" (DIEGUES, 2003, p. 09).

Nesse sentido, concorda Boff $(2015$, p.16) ao afirmar que a "sustentabilidade é um modo de ser e de viver que exige alinhamento das práticas humanas às potencialidades limitadas de cada bioma e às necessidades das presentes e das futuras gerações". Esta proposta permite que tais comunidades possam "definir seus padrões de produção e consumo, bem como o de bem-estar a partir de sua cultura, de seu desenvolvimento histórico e de seu ambiente natural" (DIEGUES, 1992, p.28). Neste sentido, não prevê um único tipo de sociedade padrão, mas visa no horizonte à existência de diversas comunidades sustentáveis pautadas nos princípios básicos da sustentabilidade ambiental, econômica e social.

Isto se dá através das construções dos diversos planos de gestão ambiental e territorial e plano de vida em terras indígenas, elaborado pelos povos indígenas de acordo com seus costumes, formas de organização e produção no território. Em um levantamento feito por Little (2006), foram encontradas quase cem iniciativas recentes no uso de etnoinstrumentos aliados a planos de "Gestão Territorial das Terras Indígenas", sendo a ampla maioria na região amazônica (83\%), seguida pelas regiões Nordeste (7\%), Centro Oeste $(4 \%)$ e Sudeste (4\%) e Sul (2\%). São exemplos de planos que já foram sistematizados em bibliografias o Plano de Gestão Territorial e Ambiental da Terra Indígena Kampa do Rio Amônia (ASSOCIAÇÃO APIWTXA, 2007), o Programa de 
Gestão Territorial e Ambiental das Terras Indígenas do Oiapoque (MAZUREK, 2013) e Aragwaksã: Plano de Gestão Territorial do Povo Pataxó de Barra Velha e Águas Belas (CARDOSO e PINHEIRO, 2012).

Em nossa abordagem, sociedades sustentáveis podem ser alcançadas em um processo que compreende conhecimento do território, planejamento e gestão através do empreendimento de ações de gestores, como o Estado, associações e/ou organizações não governamentais em articulação e sob a organização da sociedade pertencente ao território.

Acredita-se que através de um processo de gestão territorial diversificado que possa levantar as necessidades e encontrar as soluções para os problemas, pautando-se nos objetivos culturais e materiais específicos para cada povo indígena, as terras indígenas possam seguir caminhos diversificados, direcionadas a um objetivo comum, isto é, territórios de realização do "bem viver", constituindo-se em exemplos reais de sociedades sustentáveis.

\section{CONSIDERAÇÕES FINAIS}

Diante das diversas proposições de sustentabilidade e sua presença contraditória como adjetivo de desenvolvimento sustentável e a percepção de que sua formulação pode servir a propósitos contrários ao que seu discurso faz parecer, deparamo-nos com a necessidade de se adotar uma proposta que responda por harmonia e amplitude em diferentes dimensões das relações humanas, adotando-se, portanto, o conceito de modo de vida sustentável proposto por Leonardo Boff (2015).

Neste sentido, observa-se que as terras indígenas se constituem em diversos territórios com certa autonomia e diferenças culturais, ambientais, econômicas e sociais marcantes. Sobretudo, possuem o desejo de manter a sustentabilidade de seus territórios e contam com o apoio de diversos outros gestores com propósitos semelhantes.

Para alcançar seus objetivos garantindo a melhor forma de viverem segundo seus próprios costumes, os povos indígenas recorrem à "Gestão Territorial das Terras Indígenas", um conceito amplo que agrega outros conceitos como gestão ambiental, gestão territorial etnozoneamento, desenvolvimento territorial entre outros, e que através deste conceito as sociedades indígenas podem articular diversos interesses juntamente com instituições governamentais e não governamentais, entre outros agentes, que visam tanto o desenvolvimento sustentável/conservação ambiental quanto a garantia dos direitos étnicos e territoriais.

Identifica-se que o compromisso em primeiro lugar é com a qualidade de vida, com base na existência de princípios éticos baseados na vida coletiva e no cuidado com o ambiente, que são características facilitadoras para a implementação de um projeto de sustentabilidade. Assim, devem ser estimuladas a presença de capital social e humano, com vista à participação e autonomia dos projetos desenvolvidos, para que estes sigam independente da presença de agentes externos.

Compreende-se que a presença dos princípios éticos e sustentáveis possibilita a estas sociedades construir ações que visem retorno direto em qualidade de vida. Neste sentido, ações que envolvem a dimensão econômica devem buscar iniciativas baseadas em valores de solidariedade, cooperação e coletividade. A existência de valores de sustentabilidade intrínsecos na cultura, atuam como fator de união em prol da harmonia entre as atividades humanas e o meio ambiente, fortalecendo a continuidade do projeto de acordo com os objetivos inicialmente definidos. 
Acredita-se que através das ações de gestão territorial, as qualidades específicas das terras indígenas possam ser exaltadas, os desafios superados e estas possam se constituir em sociedades sustentáveis territorialmente diversificadas, as quais definem seu futuro a seu modo, reforçando cada vez mais a integração entre o homem e meio ambiente como parte de um só sistema.

\section{NOTAS}

1. Cabe esclarecer que não há uma grafia exata para o conceito, pois muitas vezes este é utilizado como "gestão territorial de terras indígenas", "em terras indígenas", "das terras indígenas", "gestão territorial indígena" com até mesmo formas de escritas diversas em mesmas obras. Todos estes termos implicam na ideia da gestão territorial (o controle político e o manejo ambiental do espaço geográfico que é o território de um grupo social ou entidade política (LITTLE, 2006, p.21) aplicada as terras indígenas (grupo social e entidade política específica). Assim optou-se por grafar "Gestão Territorial das Terras Indígenas" para deixar claro que se trata de um tipo específico de gestão territorial e manter uma forma única de escrita do conceito em todo o texto.

2. A economia solidária é outro modo de produção, cujos princípios básicos são a propriedade coletiva ou associada do capital e o direito à liberdade individual. Ver: SINGER, Paul. Introdução à Economia Solidária. São Paulo: Fundação Perseu Abramo, 2002, p.10.

3. Mais informações podem ser encontradas no site Povos Indígenas no Brasil mantido pelo Instituto Sócio Ambiental - ISA, instituição de referência em assuntos indígenas.

\section{REFERÊNCIAS BIBLIOGRÁFICAS}

ACOSTA, Alberto. O Bem Viver: Uma oportunidade para imaginar outros mundos. São Paulo. Autonomia Literária, Elefante. 2016

ANTEAG - Associação Nacional dos Trabalhadores e Empresas de Autogestão e Participação Acionária (Org). Atlas da Economia Solidária no Brasil: 2005-2007. São Paulo: Todos os Bichos. 2009.

ASSOCIAÇÃO APIWTXA. Plano de gestão territorial e ambiental da terra indígena Kampa do Rio Amônia. Rio Branco. Comissão Pró-Índio do Acre, 2007

BOFF, Leonardo. Sustentabilidade: O que é - O que não é. Petrópolis: Editora Vozes. $4^{\circ} \mathrm{Ed} .2015$.

BOISIER, Sergio. et al. Sociedad civil, atores sociales y desarrollo regional. Santiago do Chile: Ilpes/Cepal, 1995.

BUARQUE, Sergio C. Metodologia de planejamento do desenvolvimento local e municipal sustentável: Material para orientação técnica e treinamento de multiplicadores e técnicos em planejamento local e municipal. Brasília. 1999.

CANDIOTTO, Luciano Zanetti P. Uma reflexão sobre ciência e conceitos: o território na Geografia. In: Território e desenvolvimento: diferentes abordagens. RIBAS, Alexandre 
Domingues; SPOSITO, Eliseu Savério; SAQUET, Marcos Aurélio (Orgs). Francisco Beltrão: Unioeste, 2004.

CARDOSO, Thiago Mota; PINHEIRO, Maíra Bueno (Orgs). Aragwaksã: Plano de Gestão Territorial do Povo Pataxó de Barra Velha e Águas Belas. Brasília. FUNAI/CGMT/CGETNO/CGGAM, 2012.

DIAS, Roberto dos Anjos. Sem tekoha não há teko: o material e o imaterial na construção do território Avá-Guarani. Monografia. Unioeste. 2014.

DIEGUES, Antônio Carlos. Desenvolvimento Sustentável ou Sociedades Sustentáveis: da crítica do modelo aos novos paradigmas. In: São Paulo em Perspectiva, v.06. p. 2229. Jan/jun. 1992.

\section{Desenvolvimento Sustentável ou Sociedades} Sustentáveis: da crítica do modelo aos novos paradigmas. Disponível em: <http://www.ppgcasa.ufam.edu.br/pdf/Diegues_sustentabilidade.pdf >. Acesso em: Jul. 2015.

DEPRÁ, Giseli. O lago de Itaipu e a luta dos Avá-Guarani pela terra: representações na imprensa do Oeste do Paraná (1976-2000). Dissertação (Mestrado em História) Universidade Federal da Grande Dourados, Dourados, 2006.

FREY, Klaus. Capital social, comunidade e democracia. In: Política \& Sociedade. V. 02. p. 175-187, abr. 2003.

FUNAI. Terras Indígenas. Disponível em: <http://www.funai.gov.br/index.php/indiosno-brasil/terras-indigenas > Acesso em: Set. 2016.

GAIGER, Luiz Inácio. G (Coord.) A Economia Solidária no Brasil: uma análise de dados nacionais. São Leopoido. Oikos. 2014

GTZ - Deutsche Gesellschaft für Technische Zusammenarbeit. Gestão Ambiental e/ou Territorial de/em Terras Indígenas: Subsídios para a construção da Política Nacional de Gestão Ambiental em Terras Indígenas conforme Portaria Interministerial $\mathrm{n}^{\circ}$ 276/2008. Brasília. 2009.

HAESBAERT, Rogério. O mito da desterritorialização: do "fim dos territórios" à multiterritoralidade. Bertrand Brasil. Rio de Janeiro - RJ. $6^{\circ}$ ed. 2006.

LITLLE, Paul. Relatório final: Gestão Territorial em Terras Indígenas: Definição de conceitos e propostas de diretrizes. Rio Branco - Acre. 2006.

MANCE, Euclides André. Fome Zero e Economia Solidária: O desenvolvimento sustentável e a transformação estrutural do Brasil. IFiL-Editora Popular. Curitiba. 2004.

MAZUREK. Rosélis Remor de Souza (Orgs). Programa de gestão territorial e ambiental das terras indígenas do Oiapoque. Belém. The Nature Conservancy, 2013. 
MONTIBELLER-FILHO, Gilberto. Crescimento econômico e sustentabilidade. In: Sociedade \& Natureza, Uberlândia, v. 19, n.1, p. 81-89, jun. 2007.

RAFFESTIN, Claude. Por uma geografia do poder. Tradução de Maria Cecília França. São Paulo. Ática. 1993.

RAMBO, Anelise. Graciele; RUCKERT, Aldomar Arnaldo. Desenvolvimento territorial e escalas geográficas de poder e gestão - o caso da Cooperacana, Porto Xavier-RS. In: Geosul, Florianópolis - SC. v. 23, nº 46, p. 95-114, jul./dez. 2008.

RCA - Rede de Cooperação Alternativa -. Gestão territorial e ambiental em terras indígenas na Amazônia brasileira: os percursos da Rede de Cooperação Alternativa. São Paulo. 2013.

SAQUET, Marcos Aurélio. Por uma Geografia das territorialidades e das temporalidades: uma concepção multidimensional voltada para a cooperação e para o desenvolvimento territorial. $2^{\circ}$ ed. Rio de Janeiro. Consequência, 2015.

SINGER, Paul. Introdução à Economia Solidária. SP: Fundação Perseu Abramo, 2002.

SMITH, Maíra; GUIMARÃES, Marco A. Gestão ambiental e territorial de Terras Indígenas: reflexões sobre a construção de uma nova política indigenista. Florianópolis. In: Anais do Encontro da Associação de Pesquisa e Pós - Graduação em Ambiente e Sociedade. p. $01-19.2010$.

SOUZA, Cássio; ALMEIDA, Fábio. Gestão territorial em terras indígenas no Brasil. Brasília. Ministério da Educação, Secretaria de Educação Continuada, Alfabetização, Diversidade e Inclusão. Unesco. Coleção educação para todos, v. 39. Série vias dos saberes. n. 6. 2012. 